\title{
Vertebral Artery Dissection after Radiation Therapy: A Case Report
}

\author{
Raffaele Nardone ${ }^{\mathrm{a}} \quad$ Alessandro Venturi $^{\mathrm{b}}$ Anton Wieser ${ }^{\mathrm{b}} \quad$ Frediano Tezzon $^{\mathrm{a}}$ \\ Fabio Carduccic Max Windegger ${ }^{\mathrm{b}}$ Konrad Psenner ${ }^{\mathrm{b}}$ \\ Departments of ${ }^{\mathrm{a}}$ Neurology, ${ }^{\mathrm{b}}$ Radiology and ${ }^{\mathrm{c} O t o r h i n o l a r y n g o l o g y, ~ F . ~ T a p p e i n e r ~ H o s p i t a l, ~ M e r a n o, ~ I t a l y ~}$
}

Dear Sir,

Cervicocerebral arterial dissection (CAD) is increasingly recognized as an important cause of ischemic stroke in young and middle-aged individuals; they are most common between the ages of 35 and 50 years, with a peak incidence in the fifth decade [1], and account for nearly $20 \%$ of strokes in patients under 45 years [2]. Among them, internal carotid artery dissection is much more common than vertebral artery dissection (VAD).

The pathophysiology of arterial dissection is incompletely understood. A history of preceding neck trauma is common although not universal. Numerous constitutional and environmental risk factors have been postulated to explain the occurrence of the spontaneous dissections.

The occasional association with intracranial aneurysms, arterial redundancies, aortic root dilatation, common carotid artery distensibility increase, fibromuscular dysplasia, several inherited connective disorders such as Ehlers-Danlos syndrome and Marfan's syndrome suggest an underlying abnormality related to extracellular matrix deficit which could predispose to dissection. Other factors associated with dissection, such as migraine, $\alpha_{1}$-antitrypsin deficiency, hyperhomocysteinemia, suggest arterial wall fragility secondary to the hyperactivity of some proteases.
CADs are characterized by a low rate of recurrence, and familial occurrence is low. These observations suggest that shortlived trigger mechanisms may play an important role in the pathogenesis of CAD.

We report for the first time a case of VAD in a man who received ipsilateral head-and-neck radiation therapy for a cancer of the base of the tongue, to illustrate that CAD should also be included among the radiation-induced vascular diseases.

\section{Case Report}

A 53-year-old man, successfully treated for a squamous cell carcinoma of the base of the tongue with interstitial radiation (32 Gy) and external radiation therapy (46 Gy), incurred 8 months later a massive stroke due to embolic occlusion of the posterior cerebral artery at origin.

The patient initially presented with acute onset, 1 day before, of ipsilateral constrictive occipital headache and (simultaneously) neck pain, accompanied by nausea and vomiting. The patient was not engaged in any activity that would promote artery dissection; there was no history of antecedent trauma and no premonitory clinical history of cerebrovascular attacks.

At admission to our Department, neurological examination revealed left hemi- paresis, left hemihypesthesia and homonymous left hemianopsia; the blood pressure was 128/84 $\mathrm{mm} \mathrm{Hg}$.

There were no prodromal transient ischemic attacks before the ischemic stroke.

Doppler ultrasonography showed signs of severe obstruction of the right vertebral artery in the absence of atherosclerosis; the other cervical vessels were normal.

Brain magnetic resonance imaging (MRI), in particular the diffusion-weighted images, revealed acute infarctions in the right occipital lobe, the right medial temporal lobe, the right ventral basal thalamus, and the right posterior limb of the internal capsule (probably abnormal origin of the anterior choroidal artery; fig. 1). Sagittal MRI showed a typical intramural dissecting hematoma in the vessel wall of the right vertebral artery as rounded hypertintense signal on $\mathrm{T}_{1}$-weighted images; fat suppression techniques differentiate clearly such intramural hematoma from the surrounding soft tissues (fig. 2). Magnetic resonance angiography (MRA) revealed irregular stenosis in the V3 and V4 segments of the right vertebral artery (fig. 3).

The patient was treated with heparin initially, and discharges on warfarin with a plan for anticoagulation for 6 months.

\section{KARGER}

Fax +41613061234 E-Mail karger@karger.ch www.karger.com www.karger.com/ene
Dr. Raffaele Nardone

Department of Neurology, F. Tappeiner Hospital, Merano (BZ)

Via Rossini, 5

IT-39012 Merano (Italy)

Tel. +39 0473264 616, Fax +390473264 449, E-Mail raffaele.nardone@asbmeran-o.it 


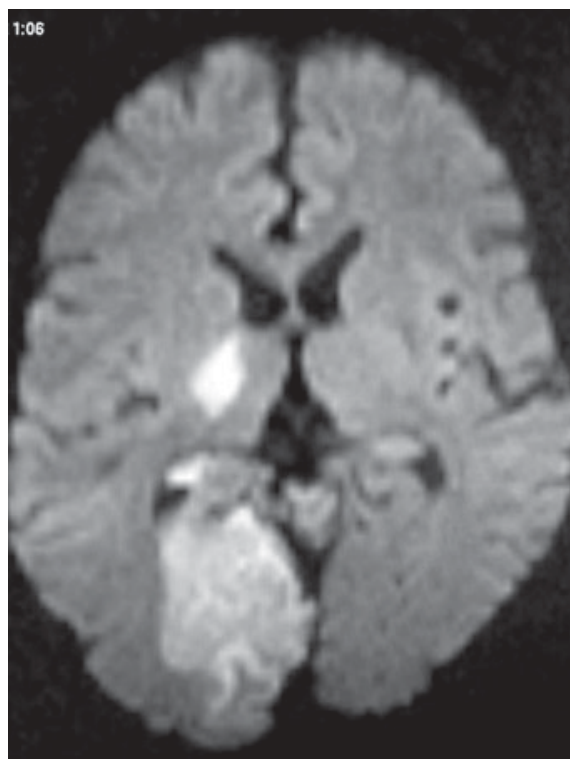

Fig. 1. Diffusion-weighted MRI showed hyperintense areas in the right occipital lobe, the right medial temporal lobe, the right ventral basal thalamus, and the right posterior limb of the internal capsule, indicating acute ischemic infarctions.

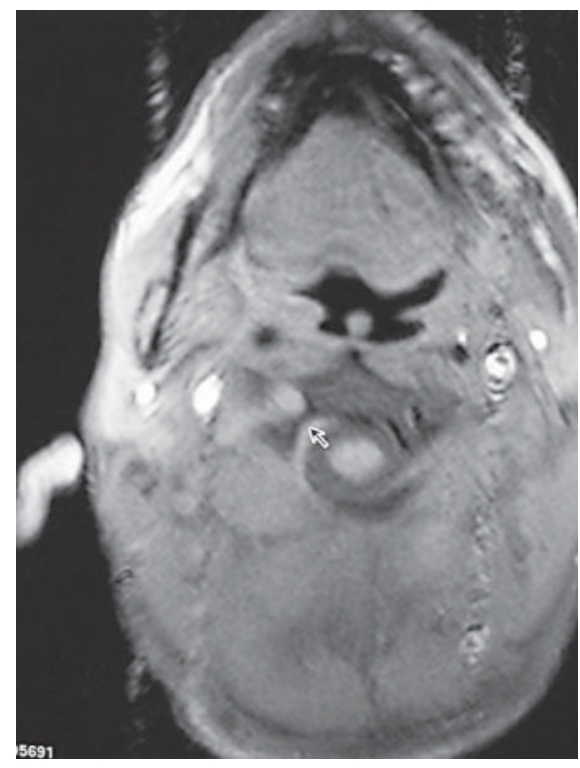

Fig. 2. Sagittal T1-weighted MRI showed a typical intramural dissecting hematoma in the wall of the right vertebral artery as rounded hyperintense signal; fat suppression techniques differentiate clearly the intramural hematoma from the surrounding soft tissues.

the increased intima media thickness $[4,5]$ and the late development of an atherosclerotic-like disorder in the arteries included in the radiation fields $[6,7]$; a carotid rupture, when radiotherapy was associated with radical neck dissection [8,9], and an early arterial occlusion within months after radiotherapy [10] have also been reported.

It is possible that the apparent injury to the large arteries is due to vasa vasorum occlusion because the microvasculature is especially vulnerable to radiation damage. There is no universal agreement as to which wall is the primary site of CAD. A rupture within the connective tissue and vasa vasorum of the media is the most probable initial event in dissection [11], even if other authors consider that an intimal tear may occur, which allows blood under arterial pressure to enter the wall of the artery [12].

Radiation therapy may also be responsible for endothelial injury which results in dissection of the vertebral artery. Irradiation may contribute to endothelial dysfunction by increasing free radical forma-

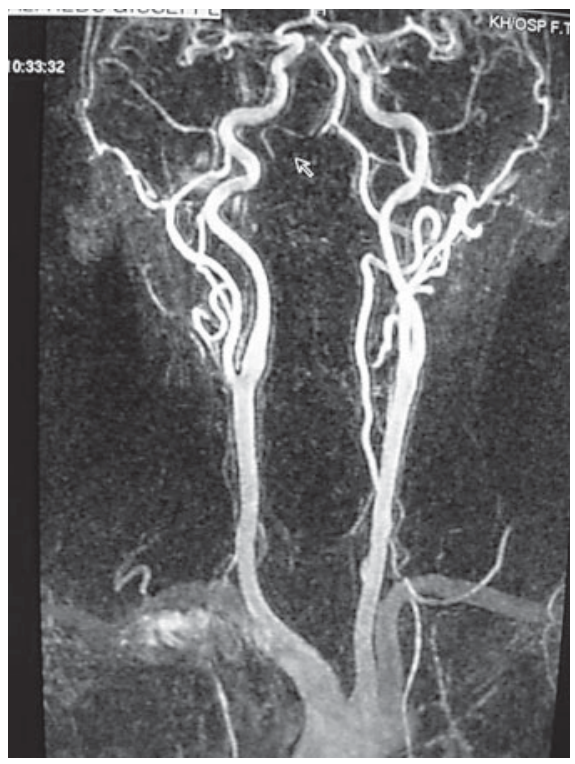

Fig. 3. MRA revealed irregular stenosis in the V3 and V4 segments of the right vertebral artery.

tion and oxidative stress, production of reactive oxygen species or by selective impairment of the nitric oxide component of endothelium-dependent vasodilatation, similar to that described in experimental studies $[13,14]$. It has been demonstrated [15] that in irradiated human cervical arteries especially the nitric oxide- and prostacyclin-mediated endothelium-dependent relaxation is impaired; the impaired nitric oxide-mediated relaxation is associated with a lack of endothelium nitric oxide synthetase expression. Recently, an evidence of impaired endothelium-dependent vasodilatation in CAD patients that is not the result of stroke [16] has been described, suggesting that an underlying arteriopathy of the arterial wall layers may predispose to CAD.

Moreover, endothelial injury induces morphologic changes of the internal elastic lamina, smooth vessel proliferation, various matrix abnormalities involving one of the fibrillar components or its enzymatic regulation, arterial wall neoangiogenesis and finally artery dissection. 
Therefore, the impaired endothelial function in irradiated human blood vessels may explain the development also of this vascular complication, and we believe that in our case a pathogenetic link might exist between radiation and VAD occurrence.

We demonstrated that it is important to identify patients who have received head and neck radiation therapy as being at risk also for dissection of cervicocerebral arteries. These subjects should be carefully evaluated for carotid or vertebral artery disease; screening and treatment of additional cerebrovascular risk factors which contribute to stroke development is recommended, especially in radiotherapy patients with a favorable prognosis.

\section{References}

1 Schievink WI, Mokri B, O'Fallon WM: Recurrent spontaneous cervical-artery dissection. N Engl J Med 1994;330:393-397.

2 Bogousslavsky J, Pierre P: Ischaemic stroke in patients under age 45. Neurol Clin 1992; 10:113-124

3 Bartels E: Dissection of extracranial vertebral artery: clinical findings and early noninvasive diagnosis. J Neuroimaging $2006 ; 16$ : 24-33.
4 So NM, Lam WW, Chook P, Woo KS, Liu $\mathrm{KH}$, Leung SF, Wong KS, Metreweli C: Carotid intima-media tickness in patients with head and neck irradiation for the treatment of nasopharyngeal carcinoma. Clin Radiol 2002;57:600-603.

5 Dorresteijn LD, Kappelle AC, Scholz NM, Mummeke M, Scholma JT, Balm AJ, Bartelin $\mathrm{H}$, Boogerd W: Increased carotid wall thickening after radiotherapy on the neck. Eur J Cancer 2005;41:1026-1030.

6 Silverberg GD, Britt RH, Goffinet DR: Radiation-induced carotid artery disease. Cancer 1978;41:130-137.

7 Murros KE, Toole JF: The effect of radiation on carotid arteries. Arch Neurol 1989;46: 449-455.

8 Mc Cready GE, Hyde GL, Bivins BA, Mattingly SS, Griffen WD: Radiation-induced arterial injuries. Surgery 1983;93:306-312.

9 Fajardo LF, Lee A: Rupture of major vessels after radiation. Cancer 1995;36:904-913.

10 Conomy JP, Kellermeyer R: Delayed cerebrovascular consequences of therapeutic radiation: a clinicopathologic study of a stroke associated with radiation-related cervical carotid arteriopathy. Cancer 1975;36:17021708.

11 Brandt T, Orbek E, Hacke W: Cervical artery dissection syndrome; in Bogousslavsky J, Caplan L (eds): Stroke Syndromes, ed 2. Cambridge, Cambridge University Press, 2001, pp 660-666.
12 Schievink W: Spontaneous dissection of the carotid and vertebral arteries. N Engl J Med 2001;344:898-906.

13 Soloviev AI, Tishkin SM, Parshikov AV, Ivanova IV, Goncharov EV, Gurney AM: Mechanisms of endothelial dysfunction after ionised radiation: selective impairment of the nitric oxide component of endothelium-dependent vasodilatation. $\mathrm{Br} \mathrm{J}$ Pharmacol 2003;138:837-844.

14 Hatoum OA, Otterson MF, Kopelman D, Miura H, Sukhotnik I, Larsen BT, Selle RM, Moulder JE, Gutterman DD: Radiation induces endothelial dysfunction in murine intestinal arterioles via enhanced production of reactive oxygen species. Arterioscler Thromb Vasc Biol 2006;26:287-294.

15 Sugihara T, Hattori Y, Yamamoto Y, Qi F, Ichikawa R, Sato A, Liu MY, Abe K, Kanno $\mathrm{M}$ : Preferential impairment of nitric oxide-mediated endothelium-dependent relaxation in human cervical arteries after irradiation. Circulation 1999;100:635-641.

16 Lucas C, Lecroart Jl, Gautier C: Impairment of endothelial function in patients with spontaneous cervical artery dissection: evidence for a general wall disease. Cerebrovasc Dis 2004; 17:124-132. 